Revista Aspas

ppgac - USP

Artigo

\title{
A COMÉDIA CEARENSE - O COMPROMISSO COM A MEMÓRIA
}

\section{THE COMÉDIA CEARENSE - COMMITMET TO MEMORY}

\section{LA COMÉDIA CEARENSE - EL COMPROMISSO CON LA MEMÓRIA}

\section{Paula Gotelip}

Paula Gotelip

Mestranda no Programa de Pós-Graduação em Teatro da Universidade do Estado de Santa

Catarina com o projeto Teatro para infância, orientado pelo Prof. Dr. Vicente Concilio, com bolsa Capes. Pesquisadora e produtora cultural.

E-mail: paulagotelip@gmail.com 


\section{Resumo}

Este trabalho apresenta o compromisso do grupo Comédia Cearense com o seu acervo e a preocupação com a catalogação e com a publicação de seus trabalhos. A Comédia Cearense foi fundada em 1957 e desde então mantém suas atividades de forma ininterrupta, tanto no teatro adulto quanto no infantil. Ao compartilhar a história do grupo e seus arquivos, descrevem-se marcos do teatro cearense e brasileiro. Palavras-chave: Casa da Comédia Cearense, Memória, Arquivo, Teatro brasileiro, Teatro de grupo.

\section{Abstract}

This work presents the Comédia Cearense group commitment with its collection and the concern with cataloguing and printing its works. The Comédia Cearense group, which was founded in 1957, has been maintaining its activities in the adult and children theater in an uninterrupted way until the current year. By sharing its history and archives, the marks of the theater from Ceará and Brazil are outlined.

Keywords: Casa da Comédia Cearense, Memory, Archive, Brazilian theater, Group theater.

\section{Resumen}

Este trabajo aborda el compromiso del grupo Comedia Cearense con su archivo y la preocupación por la catalogación y publicación de sus trabajos. La compañía Comédia Cearense fue creada en 1957 y hasta la actualidad mantiene actividades de teatro adulto e infantil de manera ininterrumpida. A través de la historia y de los archivos del grupo, se describen al mismo tiempo marcos del teatro cearense y brasileño.

Palabras clave: Casa da Comédia Cearense, Memoria, Archivo, Teatro brasileño, Teatro de grupo.

Em minha pesquisa de mestrado intitulada Processos de pesquisa e criação de teatro para crianças: um olhar a partir dos grupo: Comédia Cearense, Grupo Atrás do Pano e Cia. Experimentus, estudo grupos teatrais e seus trabalhos com a infância. Optei por trabalhar com agrupamentos teatrais por três aspectos: o primeiro é que eles tivessem suas produções destinadas à infância; o segundo que possuíssem mais de 20 anos de trabalho com o assunto; e o terceiro que estivessem localizados em diferentes regiões 
brasileiras. A partir desses aspectos, a pesquisa abrangeria o percurso histórico dos grupos em relação à infância e seus processos de criação. Dentro desse recorte serão investigados três grupos: a Comédia Cearense, com 61 anos e sediada em Fortaleza, no estado do Ceará; o Grupo Atrás do Pano, com 37 anos, com sede em Nova Lima no estado de Minas Gerais; e a Cia. Experimentus com 20 anos, na cidade de Itajaí em Santa Catarina. Todos os grupos, de alguma maneira, possuem seus acervos armazenados, sendo compostos por fotografias e vídeos - pessoais e profissionais -, recortes de jornais, arquivos de produção e administração, figurinos e cenários.

A Comédia Cearense possui seis décadas de trabalhos permanentes, como fala um dos seus fundadores, Haroldo Serra. Seus arquivos revelam a trajetória do grupo, assim como as ações formativas e de formação de plateia realizadas por eles. Para compreender um pouco mais sobre o processo de arquivamento do grupo foi realizada uma entrevista com Hiroldo Serra, filho do casal fundador Haroldo Serra, com 84 anos, e Hiramisa Serra, com 81 anos, e atual coordenador do grupo e responsável pela continuidade das ações artísticas da Comédia Cearense e da Casa da Comédia Cearense. As perguntas foram enviadas por e-mail e suas respostas vieram por escrito e estão organizadas conforme se lê abaixo. Porém, antes da entrevista descrevo um breve histórico do grupo, de forma a situar seu percurso histórico e sua preocupação com o acervo.

\section{Breve histórico}

A Comédia Cearense é considerada um dos grupos mais antigos do país. Foi fundado em 1957 e até o vigente ano (2019) atua de forma permanente no cenário teatral da cidade de Fortaleza. O grupo, que tem constituição familiar, foi considerado de Utilidade Pública pela Lei municipal no 2.821 de 11 de dezembro 1964, publicada no Diário Oficial de 17 de dezembro de 1964 da cidade em que está sediado. No ano de 1963, lançou a revista Comédia Cearense, com intenção tanto de publicar e registrar as ações desenvolvidas quanto outras ações do teatro cearense. Uma outra característica da revista é a publicação de dramaturgias, sendo que nas treze edições da revista prevalece a escolha por dramaturgos cearenses. Algumas revistas foram publicadas 
e distribuídas com o apoio do Serviço Nacional do Teatro; segundo Haroldo Serra (2002, p. 2), "várias universidades, inclusive estrangeiras, têm exemplares em suas bibliotecas". Ao longo da sua trajetória, além das revistas, o grupo produziu e publicou outros livros sobre seus trabalhos, assim como abriu espaço para que outros artistas pudessem publicar suas obras. Desde a sua fundação foram encenados 97 textos em 180 montagens, ou seja, vários textos foram remontados neste período.

No ano de 2002, fundou o espaço cultural Casa da Comédia Cearense, que entre os anos de 2009 e 2011 foi um Ponto de Cultura. O espaço cultural abriga um teatro de arena e parte do acervo do grupo, onde estão expostos cenários e figurinos de seus trabalhos e prêmios recebidos ${ }^{1}$. Há uma biblioteca onde se encontram exemplares da Revista da Sociedade Brasileira de Autores Teatrais (SBAT) e a coleção da Revista do Teatro da Juventude. Todas as salas do espaço são nomeadas com nomes importantes da história do teatro no Ceará e lá acontecem cursos e oficinas regulares e temporários gratuitos para a comunidade do entorno.

Nesses 61 anos de atividade, o grupo tem participação ativa na história e nas ações culturais do teatro cearense. Hiramisa Serra e Haroldo Serra foram diretores do Theatro José de Alencar ${ }^{2}$ e nesse espaço há diversas placas que homenageiam o grupo e seus espetáculos. Um dos espetáculos do grupo, $O$ morro do ouro ${ }^{3}$, nomeia um teatro com capacidade para cem

1. O grupo ganhou diversos prêmios dentre eles: os Prêmios Arlequim de Melhor Espetáculo com a peça $O$ simpático Jeremias no $2^{\circ}$ Festival Nacional de Teatro Amador de São José do Rio Preto em 1970. Neste mesmo festival o grupo recebeu outros nove prêmios. No ano de 1971 recebe novamente o Prêmio Arlequim no $3^{\circ}$ Festival Nacional de Teatro Amador de São José do Rio Preto com o espetáculo $O$ morro do ouro, além de outros quatros prêmios. No de 1976 recebe o Prêmio Melhores do Ano pelo Serviço Nacional de Teatro com o espetáculo infantil O planeta das crianças alegres. Em 1977 recebe o Prêmio de Melhor Espetáculo Infantil pelo Serviço Nacional do Teatro com a peça $D$. Patinha vai ser miss. O espetáculo $A$ Rosa do Lagamar rendeu indicação de Hiramisa Serra para concorrer para ao prêmio do Ministério da Educação Troféu Mambembe em 1979 e tantos outros.

2. Inaugurado em 1910 com referências arquitetônicas que mesclam o neoclassicismo e art nouveau, foi considerado Patrimônio Histórico Nacional. Trata-se de um teatro público, vinculado à Secretaria de Cultura do estado do Ceará e local de apresentações importantes do teatro cearense e do teatro brasileiro.

3. O morro do ouro, escrita por Eduardo Campos, estreou em 1963 e teve outras cinco versões encenadas pelo grupo. $O$ teatro recebeu o nome da peça, pois esta foi considerada a peça de autor cearense mais encenada na época. Em uma das versões foi musicada por Belchior, Jorge Mello e Haroldo Serra, ficando em cartaz por seis anos. Recebeu o prêmio de Melhor Espetáculo no 3ํ Festival Nacional de Teatro de São José do Rio Preto, entre 
pessoas, localizado no anexo do Theatro José de Alencar em um espaço chamado Centro de Artes Cênicas Padaria Espiritual. O grupo e seus fundadores receberam diversos prêmios nacionais e locais, seja por trabalhos individuais como atores, diretores, figurinistas, seja pelo conjunto da obra. Ainda há catalogado e publicado no livro Retrospectiva: 45 anos da Comédia Cearense, de autoria de Haroldo Serra, o registro de homenagens e prêmios recebidos até 2002, assim como o registro de todos os trabalhos encenados. Tanto no livro quanto na revista há uma sessão chamada de "teatrografia", em que são registrados o histórico das montagens acompanhados de um resumo e de um catálogo com os nomes de todos os artistas que participaram da Comédia Cearense.

No livro Comédia Cearense - 60 anos, de Hiroldo Serra, está publicado um precioso arquivo fotográfico do grupo organizado por data de estreia da primeira versão em duas vertentes: teatro adulto e teatro infantil. A publicação permite uma boa visualização das fotos, sendo possível compreender como dois signos da cena - cenário e figurino - foram elementos importantes no processo de criação do grupo ao longo dos anos.

O grupo teve como principal figurinista Hiramisa Serra, que recebeu prêmios $^{4}$ tanto por seu trabalho no teatro infantil quanto no adulto. Outro figurinista e também cenógrafo, Flávio Phebo ${ }^{5}$, premiado no teatro e no cinema, trabalhou com o grupo. No ano de 2017 o grupo, com apoio da Secretaria de Cultura do Estado, lança o livro e a exposição $O$ teatro cearense pelas mãos do cenógrafo e figurinista Flávio Phebo. Para este trabalho Hiroldo Serra, autor do livro, reuniu desenhos e fotografias de trabalhos do figurinista em sua "maior parte criados, exclusivamente para os espetáculos da Comédia Cearense" (Serra, 2017, p. 2).

outros prêmios no mesmo festival. Em 1976, Haroldo Serra dirigiu uma das montagens em São Paulo no Teatro Aplicado.

4. Hiramisa Serra recebeu como figurinistas os prêmios: Prêmio Destaque do Grupo Balaio, 1991, 1994, 1996, 2000; e o Prêmio Waldemar Garcia, 1995.

5. Como figurista em teatro recebeu alguns prêmios, dentre eles o Prêmio de Melhor Figurino no II Festival Nacional de Teatro Amador de São José do Rio Preto, 1970, Prêmio Destaque do Grupo Balaio em 1990, Melhor Figurinista de São Paulo pelo Prêmio APCA de 1976, Prêmio MEC-Troféu Mambembe de Melhor Figurino em 1977. Como cenógrafo foi premiada no ano de 1970 como Melhor Cenógrafo pelo Instituto Nacional de Cinema pelo filme A moreninha; Melhor Cenógrafo de São Paulo, Prêmio APCA em 1974. 
O acervo do grupo extrapola a capacidade da Casa da Comédia Cearense, sendo abrigado também em outros espaços, seja em galpões parceiros seja em ambientes familiares. Ao todo, são aproximadamente $900 \mathrm{~m}^{2}$ de acervo, que compreende desde objetos de cena dos primeiros espetáculos, como o boneco de Pedro Boca Rica ${ }^{6}$, até trabalhos dos alunos da Casa da Comédia Cearense.

Paula Gotelip (PG) - Durante a pesquisa de campo e as visitas tanto à Casa da Comédia Cearense quanto aos demais espaços vinculados à Comédia Cearense, eu me deparei com um volume grande de elementos cênicos (cenário, figurino, objetos de cena) e registros dos espetáculos do grupo. Como se deu este processo de arquivamento e o que motivou este processo?

Hiroldo Serra (HS) - Quando eu ainda era criança (talvez por volta de 10 anos), eu me recordo que o acervo de figurinos da Comédia Cearense ficava em dois camarins desativados no Theatro José de Alencar, em um segundo andar em cima do palco. Hoje não existem mais esses camarins. Me lembro de ficar perguntando à minha mãe de quais eram as peças de cada figurino. Também tinham alguns elementos de cenografia. Esses camarins estavam muito expostos ao sol e com o tempo esses figurinos se desgastaram um pouco; e houve também uma reforma em algum momento em que mamãe diz que desapareceram muitos figurinos. Meu pai era diretor do teatro nessa época. Vejo hoje que na verdade não havia muita preocupação em reaproveitar figurinos. Como a Comédia montava muitos espetáculos todo ano, não havia intenção de repetir nenhum naquele momento, haja visto grandes figurinos como $\mathrm{O}$ casamento da Peraldiana ${ }^{7}$ e $\mathrm{A}$ valsa proibida ${ }^{8}$, que foi montada nos anos 60 e depois em 2006 e em 1984, respectivamente. Com a saída da familia Serra da administração do TJA ${ }^{9}$, fomos para o Teatro Arena ${ }^{10}$ em 1989 e

6. Pedro Boca Rica, mestre bonequeiro cearense que dá nome também a um dos espaços anexos ao Theatro José de Alencar.

7. O casamento da Peraldiana, texto de Carlos Câmara, estreou em 1966 e ficou dois meses em cartaz. A peça é uma burleta e foram realizadas três montagens pelo grupo.

8. A valsa proibida, de Paurillo Barroso e Silvano Serra. A peça é uma opereta e foram encenadas quatro montagens pelo grupo. A primeira versão foi em 1965.

9. Theatro José de Alencar.

10. Teatro Arena Aldeota, teatro construído nas dependências do Colégio Christus a partir da concepção de Haroldo Serra. É um teatro de arena com 466 poltronas, sete metros de 
levamos as produções de Os fuzis da senhora Carrar ${ }^{11}$ e do infantil Romão e Julinha ${ }^{12}$; nesse momento era tudo que tínhamos. Com a criação do Arena e o apoio do Colégio Christus, começamos a guardar nosso acervo de figurinos em baús no próprio Arena, junto à cabine de luz. À proporção que o acervo cresceu em função das muitas produções, o colégio nos cedeu um espaço maior que hoje abriga todo o acervo de cenários. $O$ acervo de figurinos hoje está concentrado na nossa sede a Casa da Comédia Cearense e temos ainda um outro quarto, onde antes tivemos um comércio, em que abrigamos parte do acervo de figurinos que já não são mais quase aproveitados. A Casa da Comédia também mantém um arquivo de fotografias expostas, cartazes de espetáculos, comentários críticos, recortes de jornais, acervo de livros e revistas de teatro, uma videoteca, banco de textos, sala de troféus, prêmios e homenagens recebidas pelo grupo, fitas cassetes com trilhas de espetácuIos, fitas em VHS e DVDs e até Super 8 de registros de alguns espetáculos do grupo. Mantém também mais de 120 croquis originais do cenógrafo e figurinista cearense Flávio Phebo, dos quais 74 estão emoldurados e fazem parte de uma exposição itinerante.

Figura 1 - Acervo de cenário da Comédia Cearense

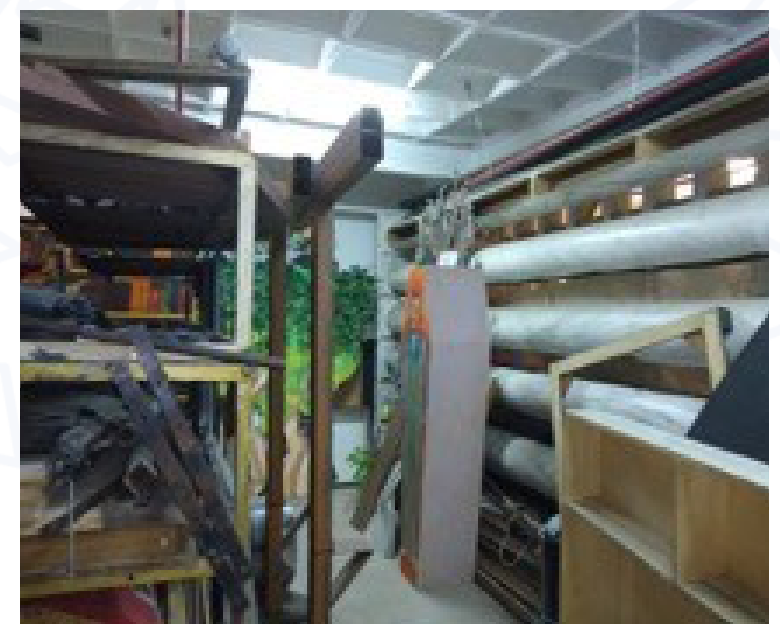

Fonte: Hiroldo Serra (2019) ${ }^{13}$

diâmetro com dois palcos laterais. Foi a base da Comédia Cearense por muitos anos e até hoje recebe seus espetáculos.

11. Os fuzis da senhora Carrar, de Bertolt Brecht, tradução de Antônio Bulhões. Estreia em 1986 com uma segunda versão em 1988.

12. Romão e Julinha, de Oscar Von Pfuhl e destinado ao público infantil, foi encenado duas vezes pelo grupo.

13. Todas as imagens foram cedidas por Hiroldo Serra mediante autorização escrita. 
Figura 2 - Acervo de cenário da Comédia Cearense

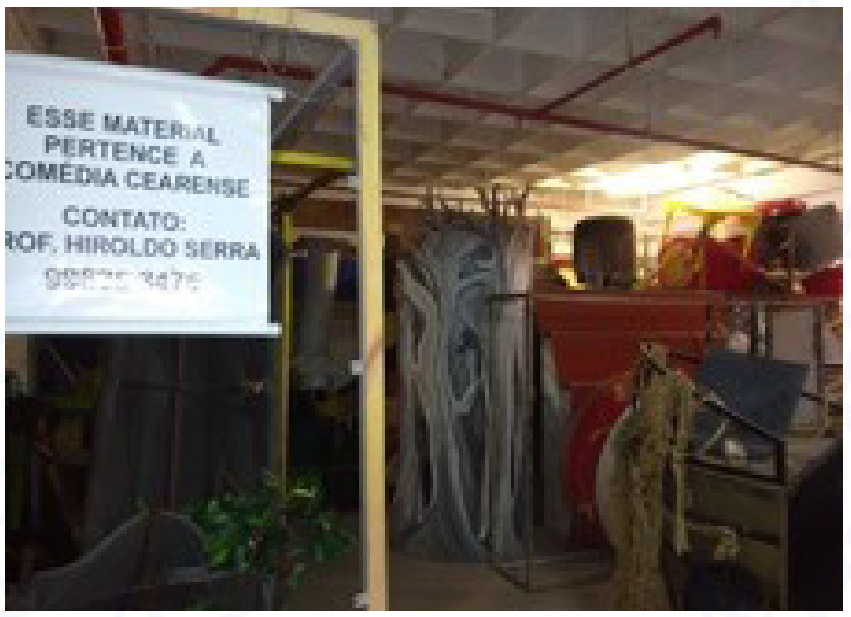

Fonte: Hiroldo Serra (2019)

Figura 3 - Acervo de figurinos da Comédia Cearense

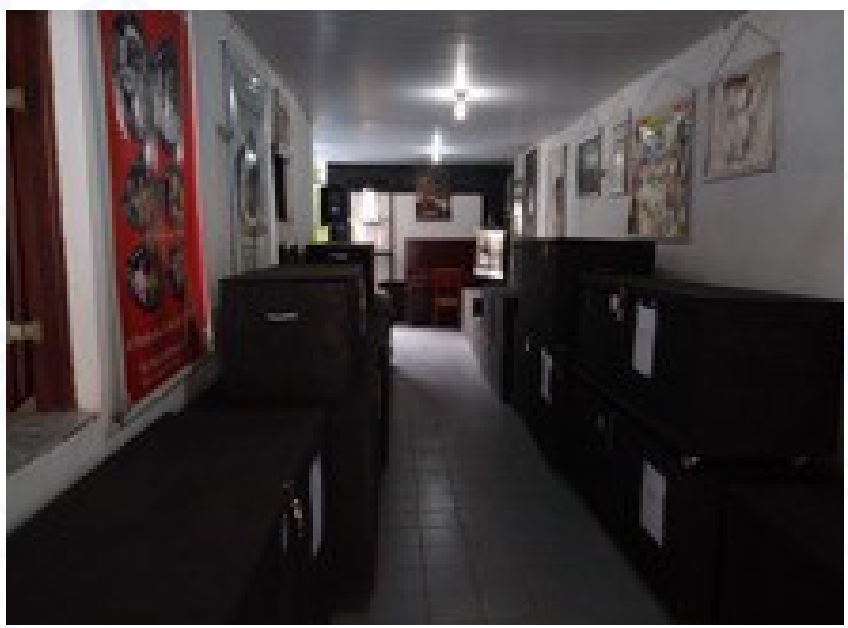

Fonte: Hiroldo Serra (2019)

Figura 4 - Acervo de figurinos da Comédia Cearense

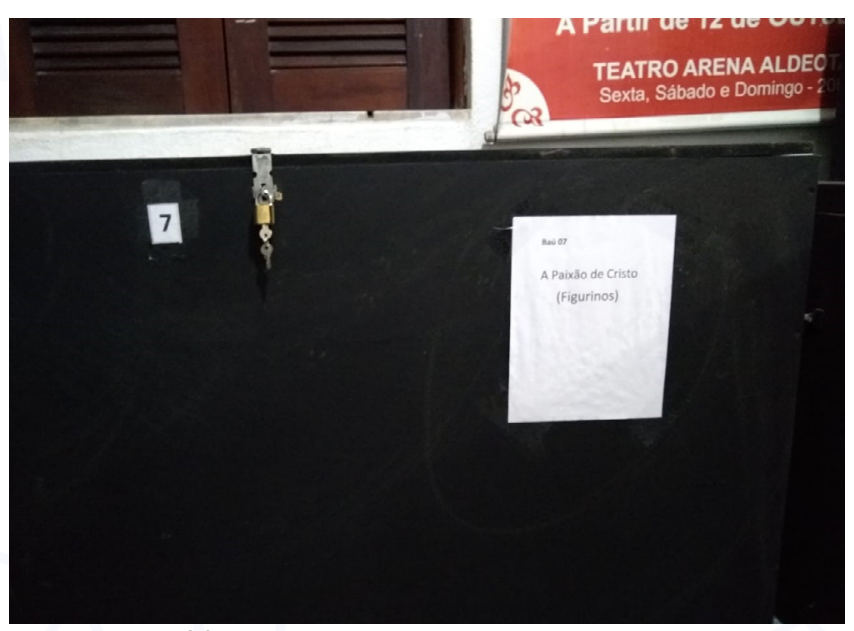

Fonte: Hiroldo Serra (2019) 
Figura 5 - Fitas cassete contento o registro das músicas do espetáculo

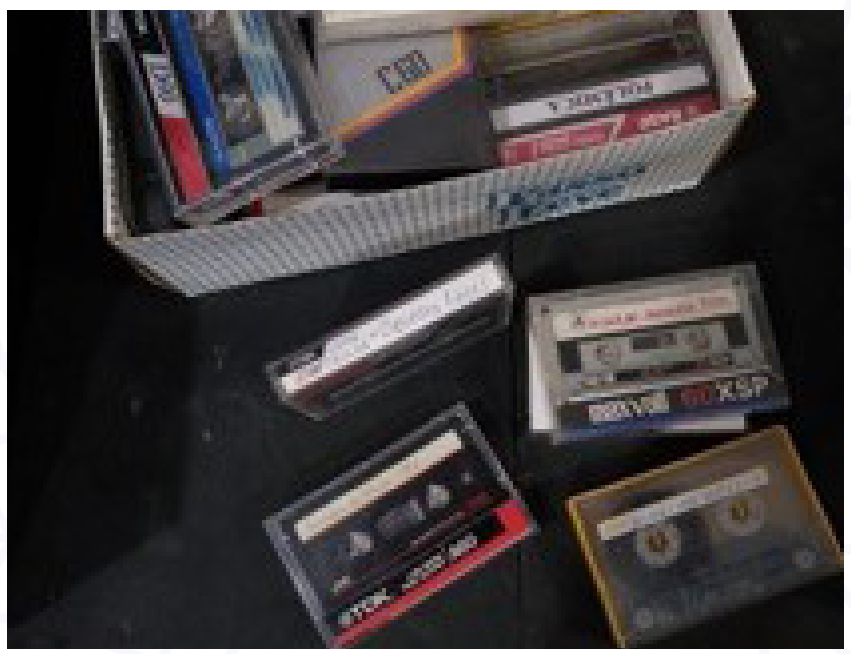

Fonte: Hiroldo Serra (2019)

Figura 6 - DVDs contendo registro dos espetáculos gravados

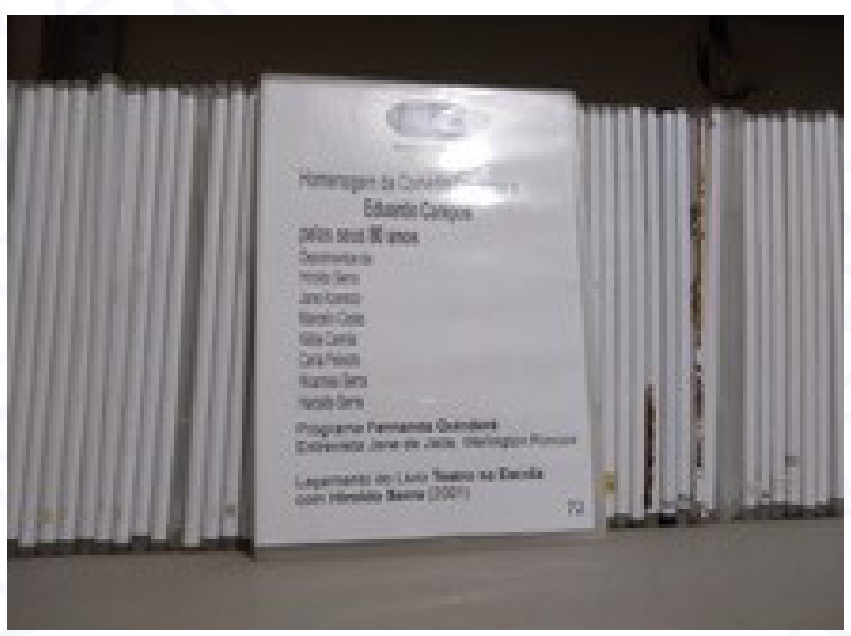

Fonte: Hiroldo Serra (2019)

Figura 7 - Acervo bibliográfico da Casa da Comédia Cearense

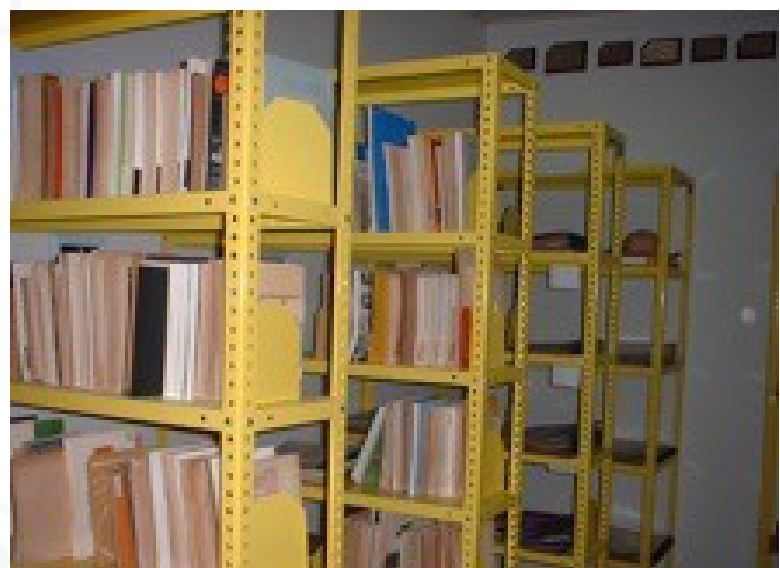

Fonte: Hiroldo Serra (2019) 
Figura 8 - Acervo de fitas cassete e DVDs disponíveis para empréstimo na Casa da Comédia Cearense

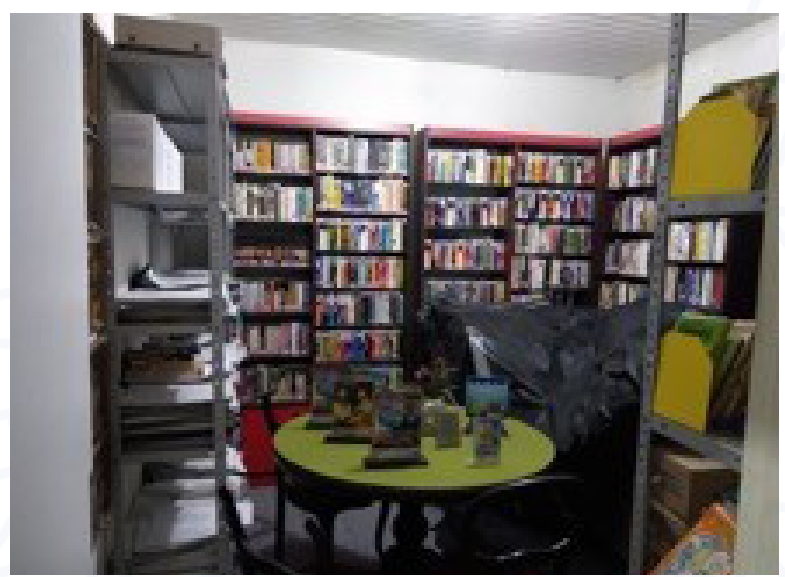

Fonte: Hiroldo Serra (2019)

Figura 9 - Área de convívio na Casa da Comédia Cearense. Nas paredes fotos dos espetáculos e os móveis que foram utilizados em cena

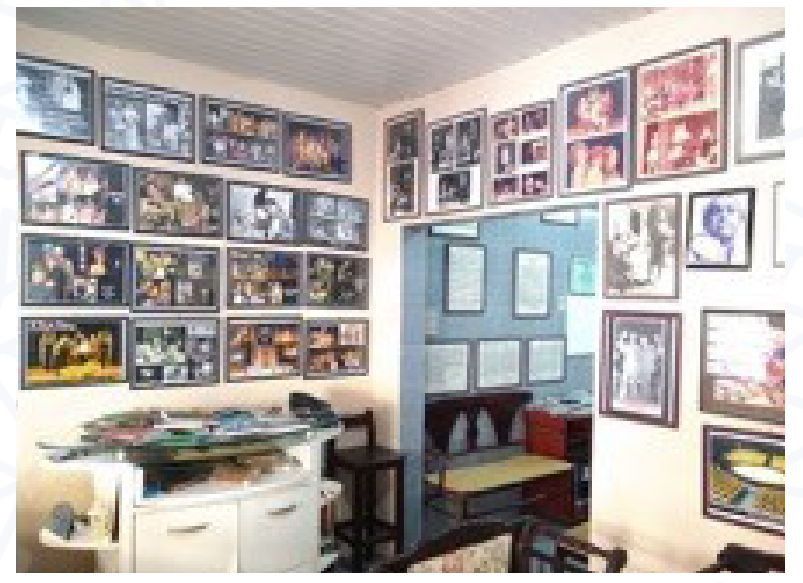

Fonte: Hiroldo Serra (2019)

Figura 10 - Espaço localizado na biblioteca da Casa da Comédia Cearense expondo homenagens e prêmios recebidos

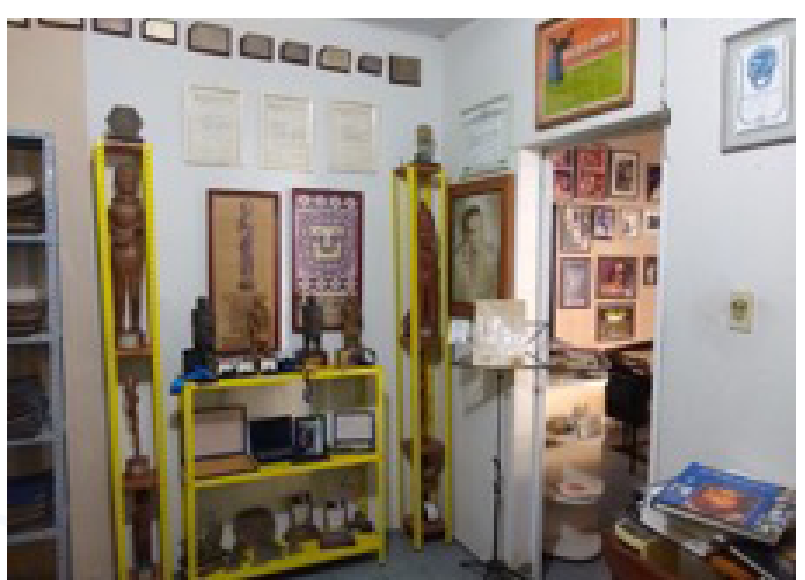

Fonte: Hiroldo Serra (2019) 
Figura 11 - Espaço localizado na biblioteca da Casa da Comédia Cearense expondo homenagens e prêmios recebidos

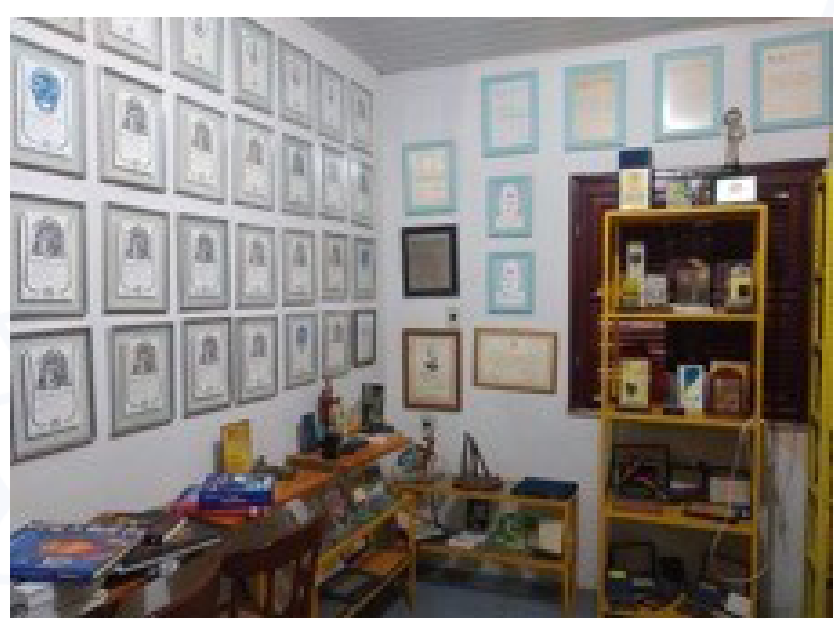

Fonte: Hiroldo Serra (2019)

Figura 12 - Cenários expostos na Casa da Comédia Cearense

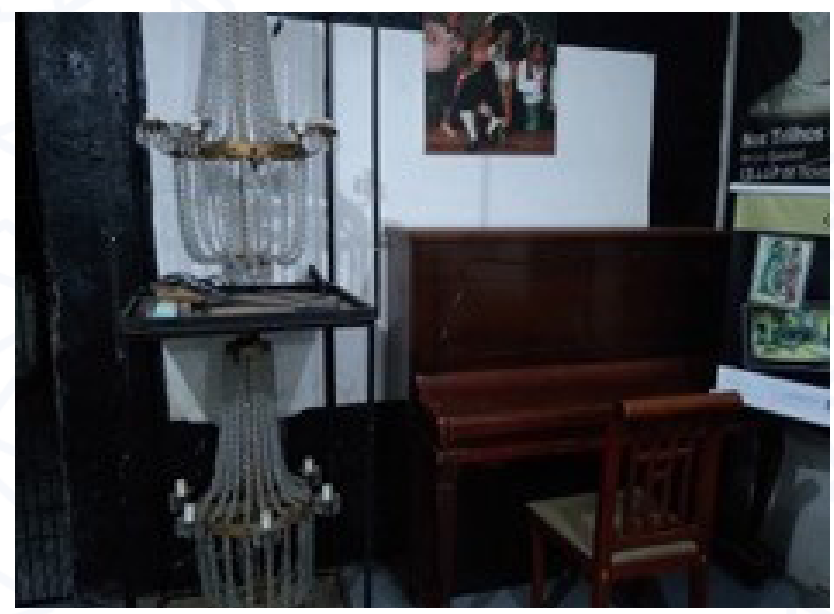

Fonte: Hiroldo Serra (2019)

Figura 13 - Cenários expostos na Casa da Comédia Cearense

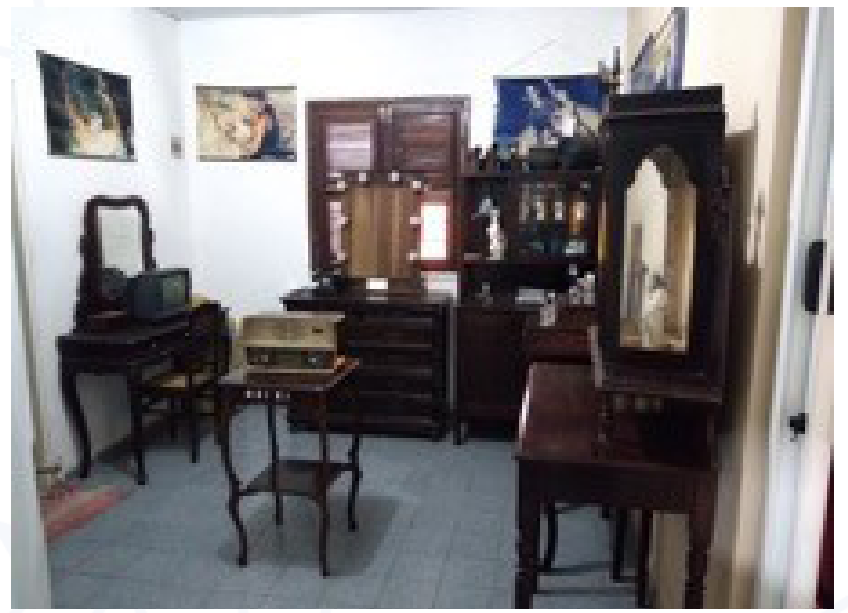

Fonte: Hiroldo Serra (2019) 
Figura 14 - Sala Flávio Phebo na Casa da Comédia Cearense. Nas prateleiras croquis e desenhos originais. Exposição de cenário e figurinos

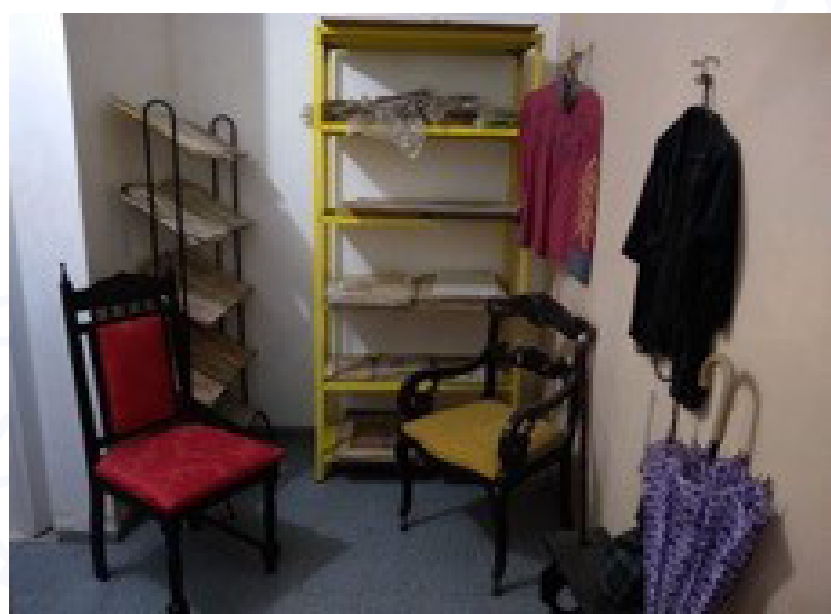

Fonte: Hiroldo Serra (2019)

Figura 15 - Teatro de arena da Casa da Comédia Cearense

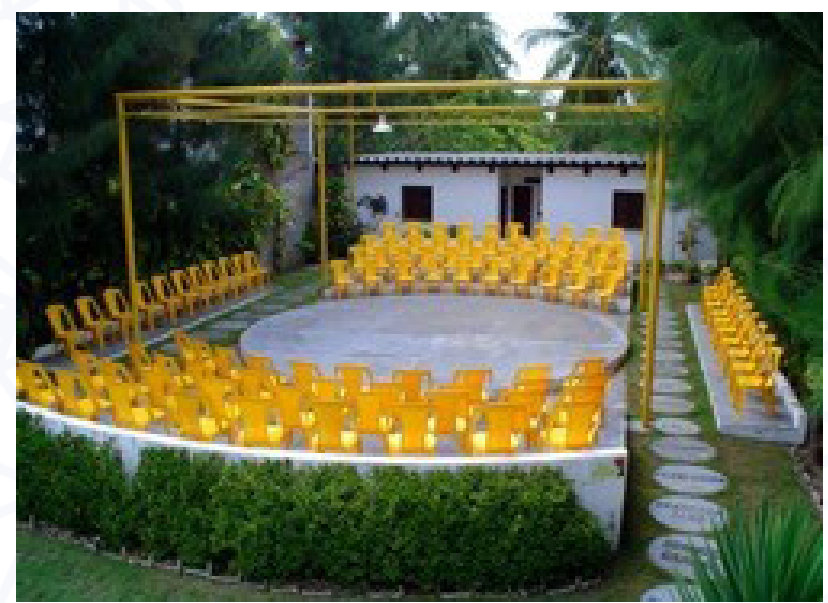

Fonte: Hiroldo Serra (2019)

Figura 16 - Expositor em exposição na Casa da Comédia Cearense

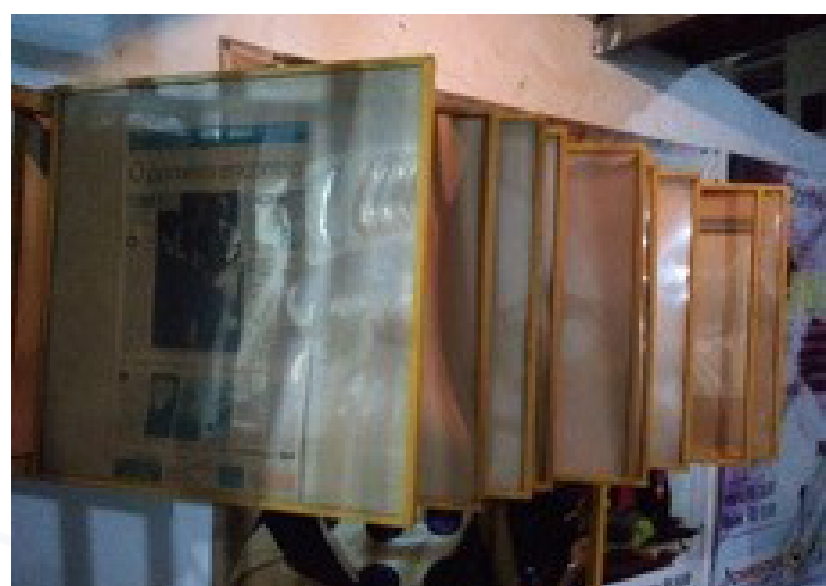

Fonte: Hiroldo Serra (2019) 
PG - A criação deste acervo é um elemento importante para o grupo. Além do acervo o Haroldo Serra pensou em uma estrutura de ferro itinerante que servia de exposição. Quais eram os materiais expostos nessa estrutura e em que ocasiões eram expostos?

HS - Essa estrutura foi criada em 2007 quando a Comédia Cearense completou 50 anos de atividades. Na ocasião estávamos montando a opereta A viúva alegre14. A estrutura abrigava os recortes de jornais que, durante sete dias, a Comédia teve páginas inteiras. Também abrigou os croquis originais de figurinos de Flávio Phebo. Hoje ele está permanente na Casa da Comédia Cearense.

Figura 17 - Expositor na Casa da Comédia Cearense

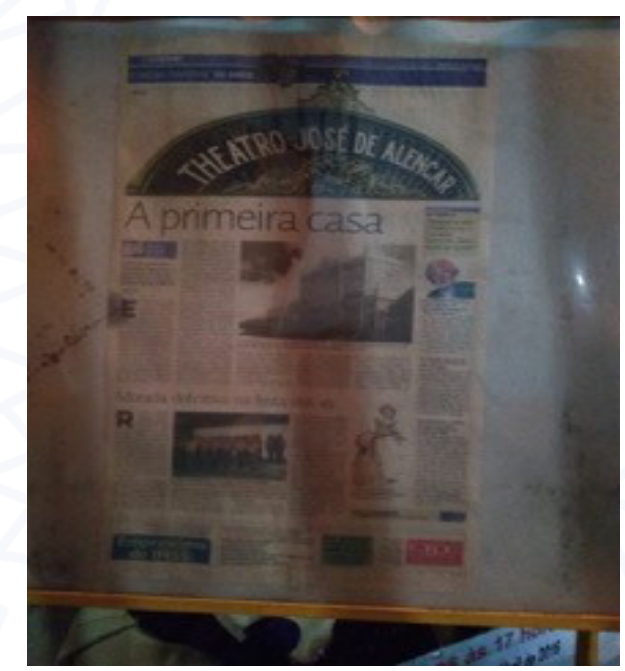

Fonte: Hiroldo Serra (2019)

PG - Nas publicações do grupo (revistas e livros), vocês utilizam o termo "teatrografia". Na seção de "Teatrografia", o leitor tem acesso a informações como o nome do espetáculo, autor da obra, diretor, atores, data, local de estreia e se foi remontado. Qual a origem do termo e como chegaram a ele?

HS - O termo teatrografia significa o registro da trajetória de um ator ou de um grupo (vi alguma coisa em italiano, mas não sei precisar se, de fato, é a origem do nome). Tanto nas revistas como nos livros da Comédia Cearense houve essa preocupação do registro de todas as atividades do grupo bem como, no caso das revistas e outras publicações, a publicação de textos de autores cearenses para que seus textos ficassem conhecidos fora do nosso estado.

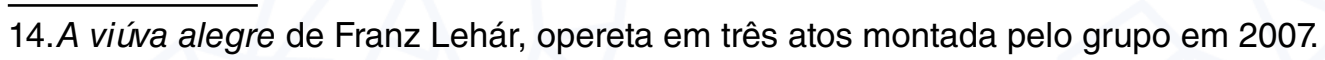


PG - Como se deu o processo de criação, publicação e registro através da revista Comédia Cearense?

HS - Provavelmente a Revista da SBAT deve ter sido motivo de incentivo. A revista da Comédia15 já começa nos anos 60 com registro de espetáculos, textos publicados e reportagens sobre teatro. Não havia uma data para lançamento dos exemplares seguintes. Em alguns volumes a Comédia teve apoio do Serviço Nacional de Teatro. Foram 13 revistas. Um livro dos 45, um dos 60 anos e outras publicações.

Figura 18 - Primeiro número da revista Comédia Cearense, publicado em 1964

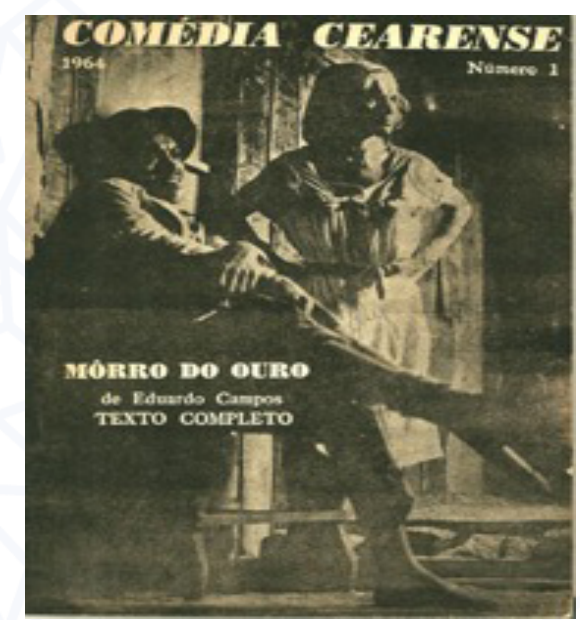

Fonte: Hiroldo Serra (2019)

Figura 19 - Revista Comédia Cearense, número 2. Publicada em 1964

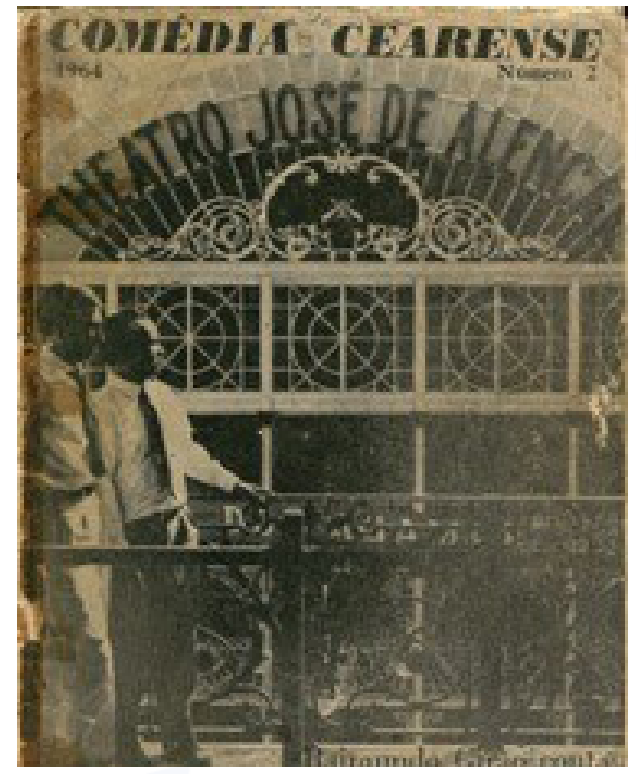

Fonte: Hiroldo Serra (2019)

15. Referente à revista Comédia Cearense. 
Figura 20 - Revista Comédia Cearense, número 3. Publicada em 1965

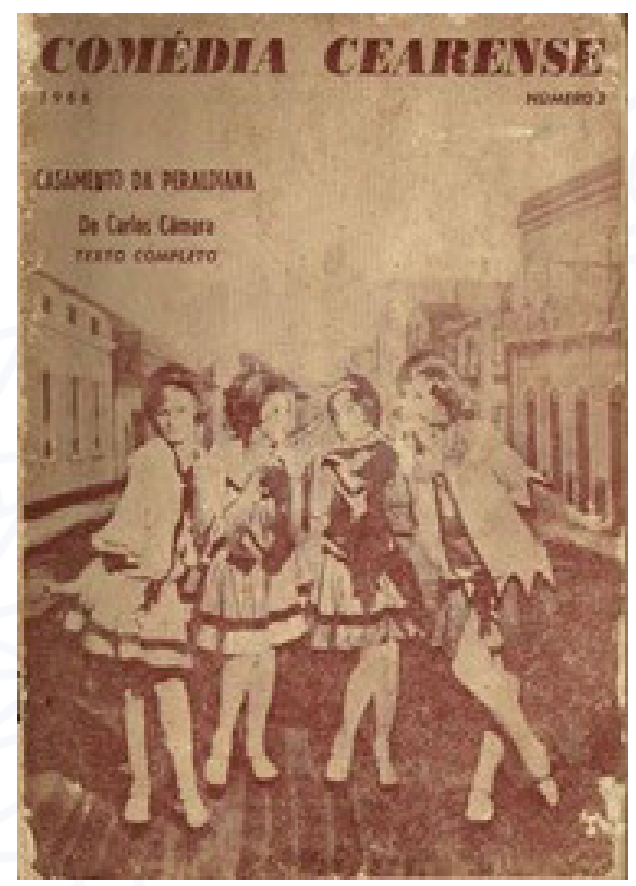

Fonte: Hiroldo Serra (2019)

Figura 21 - Revista Comédia Cearense, número 4. Publicada em 1965

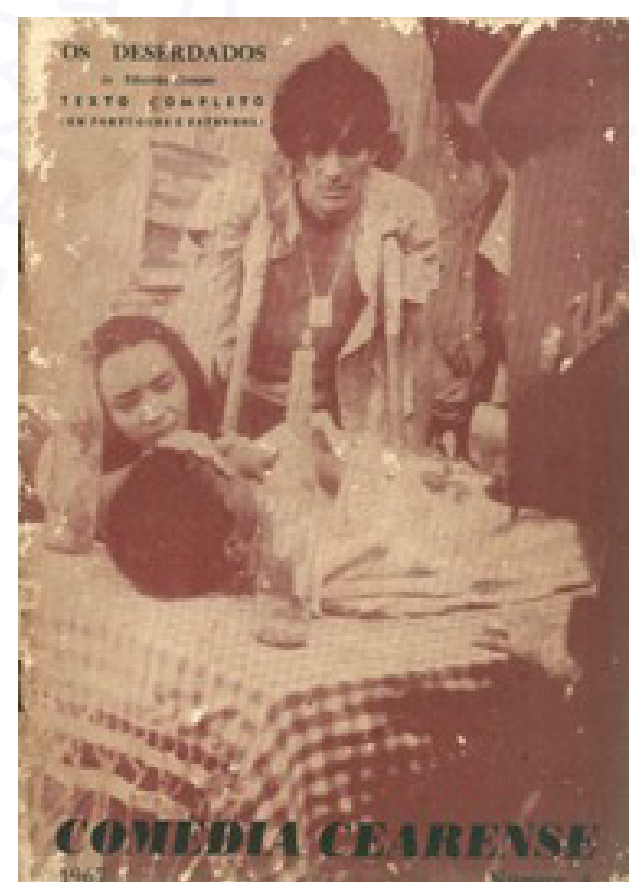

Fonte: Hiroldo Serra (2019) 
Figura 22 - Revista Comédia Cearense, número 5. Publicada em 1978

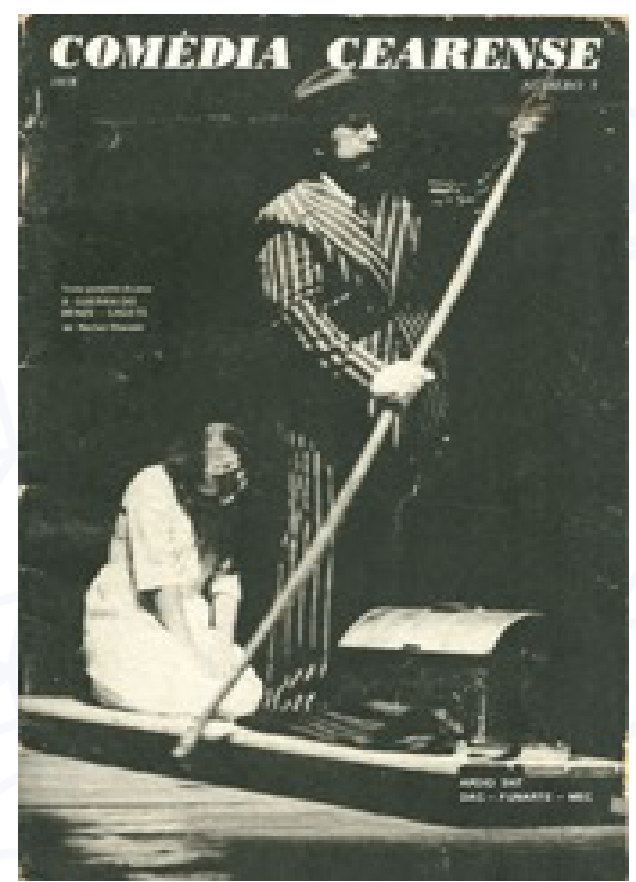

Fonte: Hiroldo Serra (2019)

Figura 23 - Revista Comédia Cearense, número 6. Publicada em 1980

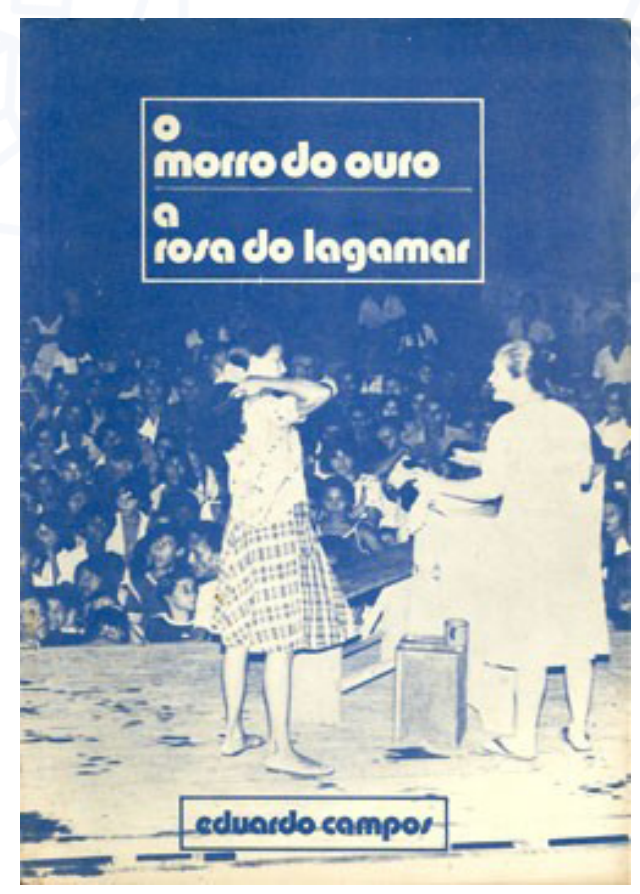

Fonte: Hiroldo Serra (2019) 
Figura 24 - Revista Comédia Cearense, número 7. Publicada em 1981

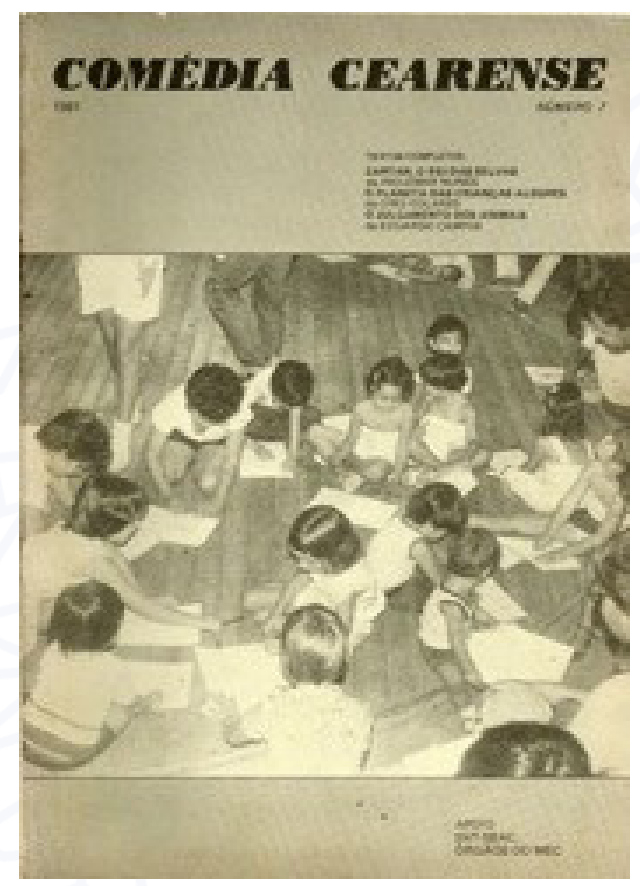

Fonte: Hiroldo Serra (2019)

Figura 25 - Revista Comédia Cearense, número 8. Publicada em 1981

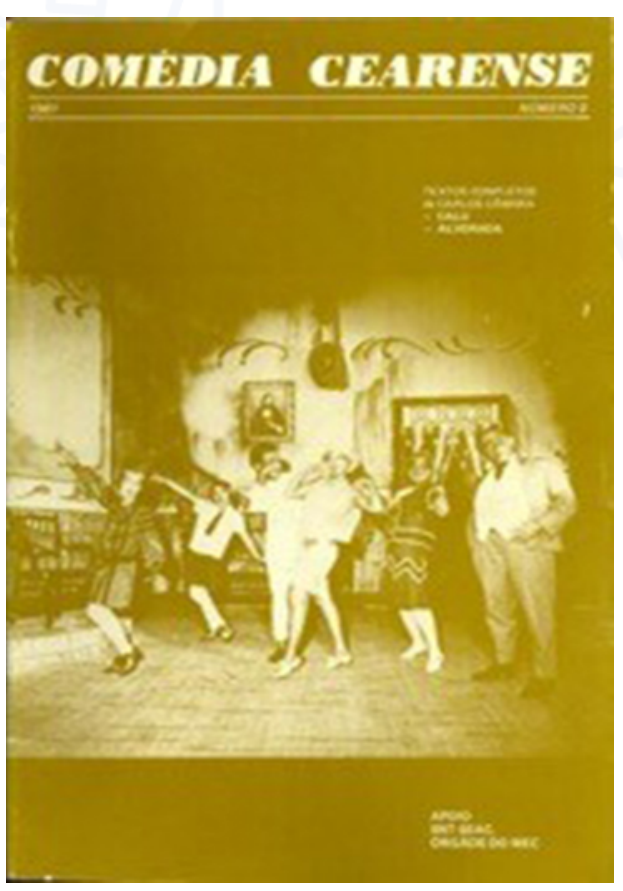

Fonte: Hiroldo Serra (2019) 
A Comédia Cearense - O Compromisso com a Memória

Figura 26 - Revista Comédia Cearense, número 9. Publicada em 1982

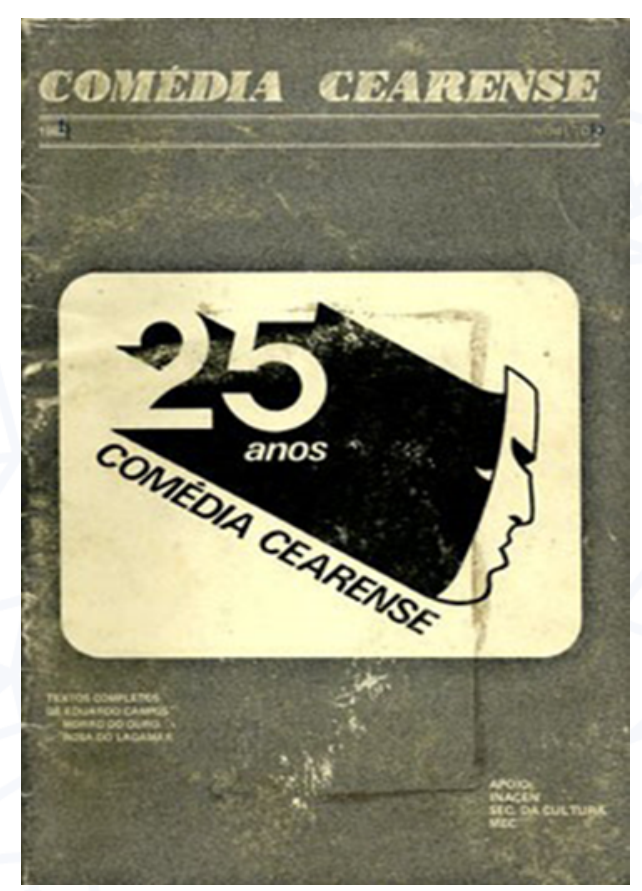

Fonte: Hiroldo Serra (2019)

Figura 27 - Revista Comédia Cearense, número 10. Publicada em 1984

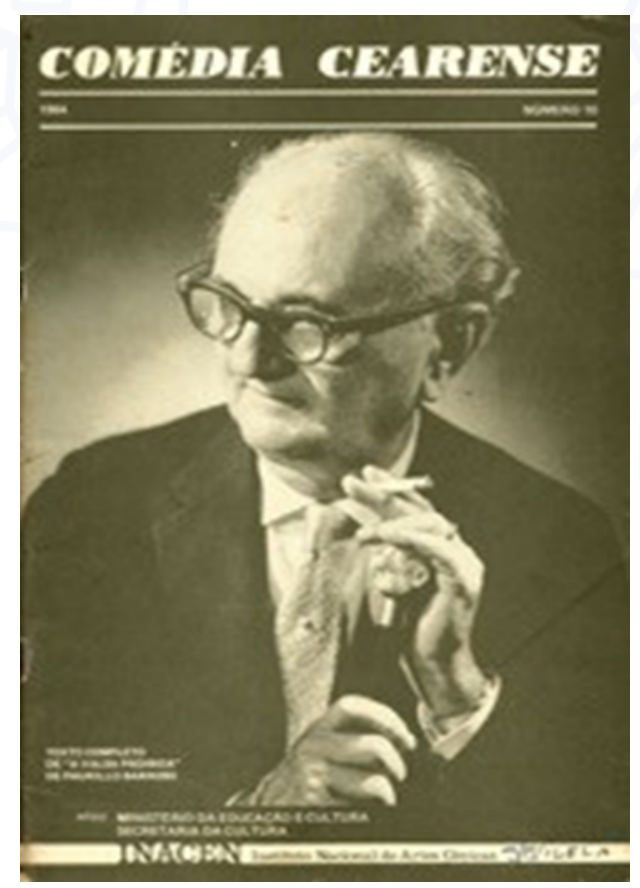

Fonte: Hiroldo Serra (2019) 
Figura 28 - Revista Comédia Cearense, número 11. Publicada em 1985

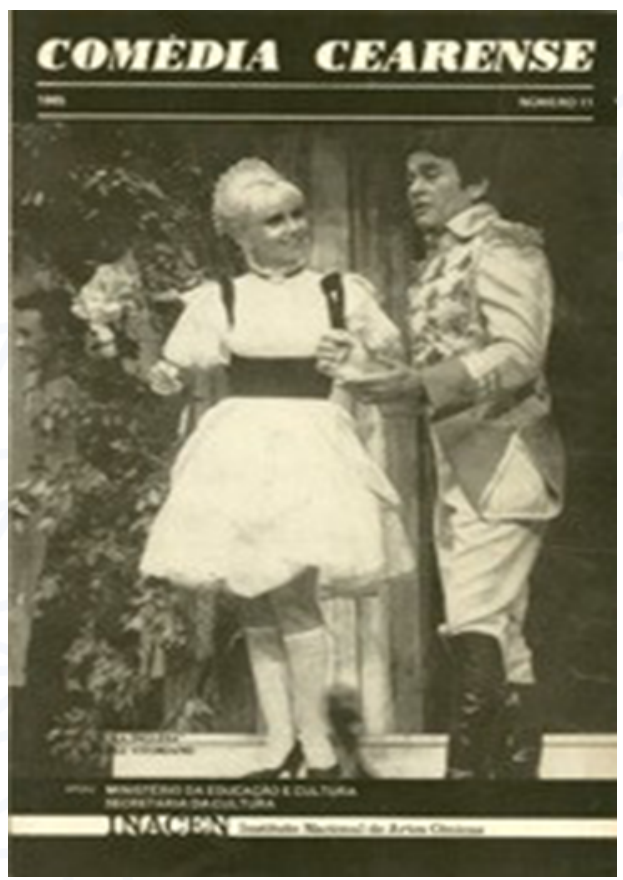

Fonte: Hiroldo Serra (2019)

Figura 29 - Revista Comédia Cearense, número 12. Publicada em 1986

\section{COMHEDA CEARENSE}

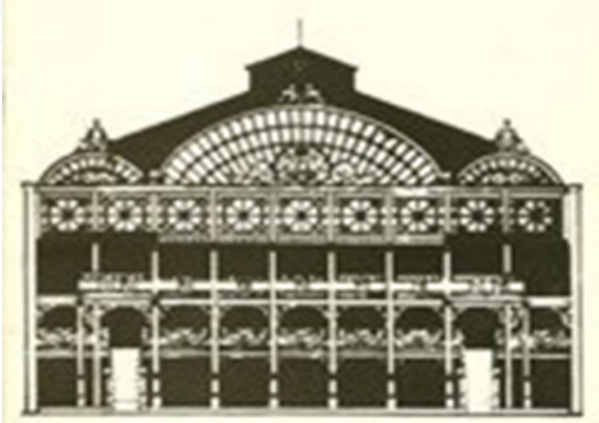

O PAO

Orwald tarrons

Matonia $\infty$ reatac

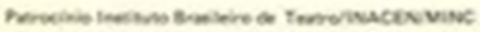

Fonte: Hiroldo Serra (2019) 
Figura 30 - Revista Comédia Cearense, número 13. Publicada em 1987

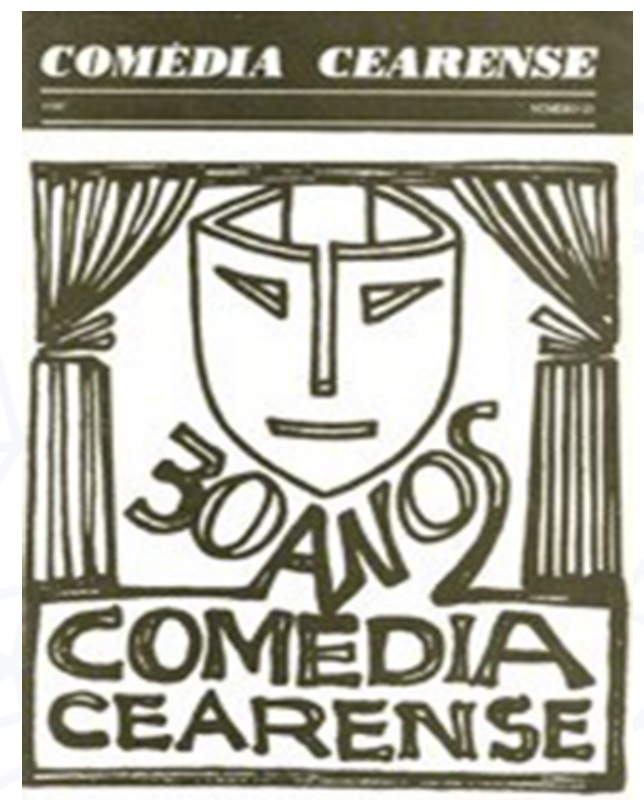

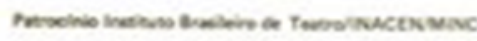

Fonte: Hiroldo Serra (2019)

PG - Há cadernos de anotações dos processos de montagens?

HS - Nunca houve um caderno para anotações dos processos de montagem.

PG - A música é um elemento de destaque nos trabalhos do grupo. Vocês têm algum registro das músicas dos espetáculos do grupo?

HS - Sim, temos vários espetáculos gravados em VHS e DVDs que contemplam tanto a peça como as músicas, e temos várias fitas cassete com trilhas antigas, CDs de trilhas mais novas e outras estão no computador.

PG - Uma outra característica do grupo é a remontagem de textos. Um mesmo texto é encenado diversas vezes ao longo da trajetória do grupo. Há registro de cada montagem? De como foram modificados os figurinos e o próprio texto? HS - Sim, temos os registros das fotos das montagens. Dependendo do tempo entre uma montagem e outra já usamos os mesmos figurinos e também já fizemos todos os figurinos novos para a segunda montagem.

PG - Vocês têm uma trajetória de 61 anos no teatro. Houve também a preocupação de criar um arquivo administrativo de produção do grupo? 
HS - Se você fala administrativo tipo quantidade de ingressos vendidos, quantos convites, custo da produção... temos esses registros de uns cinco anos para cá.

PG - Na Casa da Comédia há uma biblioteca que contém itens relevantes para a memória do teatro brasileiro e cearense, tais como as revistas Comédia Cearense e as revistas do teatro brasileiro, como a Revista da Sociedade Brasileira de Autores Teatrais e a Revista do Teatro da Juventude. Como o público pode ter acesso a este espaço?

HS - A Casa da Comédia como um todo está aberta à visitação de escolas ou pessoas interessadas em teatro e memória. As visitas são agendadas comigo e eu sempre estou presente para falar sobre o grupo.

PG - Há alguma iniciativa que visa a digitalização deste acervo para que outros pesquisadores e artistas possam ter acesso ao acervo do grupo?

HS - Nós temos boa parte do acervo fotográfico digitalizado. Essa parte de jornais e matérias em geral sobre o grupo não temos nada. Seria necessário um apoio em nível de edital para toda essa digitação.

PG - Quais os itens que consideram importantes nos acervos do grupo?

HS - Tudo que diz respeito à memória do grupo é importante. No caso da Comédia Cearense temos dois livros sobre a trajetória do grupo, além das revistas da Comédia, temos acervo de fotos e matérias de jornais, temos acervo de cenários e figurinos, fitas cassete com trilhas sonoras e CDs, vídeos e DVDs de alguns espetáculos.

\section{Referências bibliográficas}

SERRA, Haroldo. Retrospectiva: 45 anos da Comédia Cearense. Fortaleza: Editora Comédia Cearense, 2002.

SERRA, Hiroldo. $O$ teatro cearense pelas mãos do cenógrafo e figurinista Flávio Phebo. Fortaleza: Gráfica LCR, 2017.

Recebido em 15/02/2019 Aprovado em 22/05/2019

Publicado em 29/08/2019 